\title{
Seismic activity and thermal regime of low temperature fumaroles at Mt. Vesuvius in 2004-2011: distinguishing among seismic, volcanic and hydrological signals
}

\author{
Paola Cusano $^{1, \star}$, Simona Petrosino ${ }^{1}$, Paolo Madonia $^{2}$, Cinzia Federico ${ }^{2}$ \\ ${ }^{1}$ Istituto Nazionale di Geofisica e Vulcanologia, Sezione di Napoli, Osservatorio Vesuviano, Naples, Italy \\ ${ }^{2}$ Istituto Nazionale di Geofisica e Vulcanologia, Sezione di Palermo, Palermo, Italy
}

\section{Article history}

Received August 29, 2012; accepted January 3, 2013.

Subject classification:

Surveys, measurements and monitoring, Seismicity, Fumarolic thermal regime, Multidisciplinary data comparison, Rest state definition.

\begin{abstract}
Seismological, soil temperature and hydrological data from Mt. Vesuvius are collected to characterize the present-day activity of the volcanic/hydrothermal system and to detect possible unrest-related phenomena. We present patterns of seismicity and soil temperature in the crater area during the period February 2004-December 2011. The temporal distribution of number and depth of Volcano-Tectonic earthquakes and the energy release are considered. Hourly data of soil temperature have been acquired since January 2004 in different locations along the rim and within the crater. The observed changes of temperature are studied to establish a temporal-based correlation with the volcanic activity and/or with external forcing, as variations of the regional and local stress field acting on the volcano or meteorological phenomena. The comparison between seismic activity and temperature data highlights significant variations possibly related to changes in fluid circulation in the hydrothermal system of the volcano. The common continuous observations start just before a very shallow earthquake occurred in August 2005, which was preceded by a thermal anomaly. This coincidence has been interpreted as related to fluid-driven rock fracturing, as observed in other volcanoes. For the successive temporal patterns, the seismicity rate and energy release are characterized by slight variations accompanied by changes in temperature. This evidence of reactivity of the fumarole thermal field to seismic strain can be used to discriminate between tectonic and volcanic signals at Mt. Vesuvius.
\end{abstract}

\section{Introduction}

In outlining the state of a volcanic system and its evolution, several parameters have to be monitored and analyzed. In the last decades, the technological progress has allowed the acquisition of a huge amount of data of different nature (seismological, geochemical, volcanological, geodetic, etc.), with a dense spatial distribution inside an area of interest and on long time intervals (from several years to decades).

Among the seismic-derived parameters, seismicity rate and energy release play an important role in volcano monitoring since their temporal variations could be indicators of changes in the acting stress field. Furthermore, useful insights into the source processes are provided by hypocenter locations.

Likewise, variations in the chemistry, temperature and mass rate of volcanic fluids (steam, water, $\mathrm{CO}_{2}$ ) could be linked to important dynamic processes. Since the fluids circulating in a volcanic area easily result from the mixing of hydrothermal, volcanic and shallow meteoric sources, it is essential to attribute the correct interpretation to the any observed anomaly. Anomalies can be due to: (1) variations in the volcanic 'deep' source; (2) changes in soil permeability due to the local or regional stress field acting on the volcano; (3) modifications of the hydrological regime, with variable amounts of meteoric waters entering the volcanic edifice.

Recently multidisciplinary approaches have been introduced by researchers to characterize the activity of many volcanoes. D'Auria et al. [2011] analyzed a multiparametric dataset of seismological, geodetic and geochemical data recorded at Campi Flegrei caldera (southern Italy) in the period 1982-2010 and provided further constraints to quantitative models of the Campi Flegrei geothermal system. In particular, the authors highlighted the timing between the onset of the uplift and the occurrence of Long-Period (LP) and VolcanoTectonic (VT) events. Moreover, basing on the results of this work, the authors have argued the improvement of microseismicity detection in the development of the monitoring networks. 
Mauri et al. [2012] presented a groundwater flow model that highlights the existence of active volcanic structures cutting across the caldera floor of Masaya volcanic complex (Nicaragua). By using 5 years of selfpotential, ground temperature and soil $\mathrm{CO}_{2}$ surveys, from 2006 to 2010, they obtained a multi-scale wavelet tomography showing that the shallowest groundwater flow mimics the topography and that uprising fluids are of hydrothermal origin. Even if in the analyzed period the volcano was in a steady state, the adopted technique delineated the active subsurface structures of the caldera and permitted the monitoring of the hydrothermal system, whose fluctuations may precede important changes in the volcanic activity.

In order to understand the magmatic-hydrothermal interactions that can lead to phreatic eruptions at Meakandake volcano, Shinohara et al. [2011] monitored temperature, composition and emission rate of the three fumarolic fields existing on the volcano, from 2003 to 2008. Their observations allowed to characterize the temporal evolution of Meakandake volcanic activity that preceded the 2006 phreatic eruption and its evolution. The authors were able to recognize a magmatic-hydrothermal system for each fumarolic field, identifying which of them was linked to the 2006 eruption.

Since volcanic hazard at Mt. Vesuvius is considered one of the most critical in the world, a long-lasting multidisciplinary volcanic surveillance program has been carried out during the last decades. Monitoring allows to analyze and compare the short- and long-term evolution of different parameters.

By studying long-time series of chemical and isotopic compositions of Mt. Vesuvius fumaroles from 1998 to 2010, Caliro et al. [2011] identified the phenomena that occur on short-period, which appear to be linked to shallow processes in the hydrothermal system, and longtime variations associated to changes of volcanic activity.

Madonia et al. [2008] (hereinafter referred to as M08) compared short- and long-term variations (with timescales ranging from few days to several years) of geochemical parameters, (chemistry of groundwater and thermal regime of the fumarolic field) and seismic activity in the Vesuvius volcanic system during the 19982005 period, interpreted as having common source mechanisms.

In the present work we illustrate the progression of M08, after the updating of the seismological and geochemical data set from 2005 to 2011, for what concerns the correlations between seismicity and fumarolic activity. The relationships between seismicity and chemistry of groundwater are discussed by Federico et al. [2013]. In the following we first describe the volcanic system and the data set, then, after a brief summary of the results obtained in M08, we show the analyses performed in the period February 2004-December 2011. Finally we discuss the results on the basis of the 1999-2011 data set.

\section{Volcanological setting}

The Somma-Vesuvius volcanic complex is a stratovolcano, $1281 \mathrm{~m}$ high above sea level and $10 \mathrm{~km}$ wide. It presents a recent cone, Vesuvius, located inside the pre-existing Somma caldera. The volcanic complex is sited in the Piana Campana (southern Italy), which is bordered by Mesozoic carbonates. This structure, located between the Tyrrhenian margin and Southern Apennines, is characterized by a general normal stress field. The main fault systems strike NE-SW and NWSE and produced the graben-like morphology of the carbonate basement [Santacroce 1987, Patacca et al. 1990, Acocella and Funiciello 2006, Di Renzo et al. 2007]. The subsidence of this basement, that lays at a depth of about $2 \mathrm{~km}$ below Mt. Vesuvius, generates a wide gravimetric anomaly located in the central part of the Campanian Plain, defining an area named the Acerra graben [Scandone et al. 1991, Marzocchi et al. 1993]. The structural depression is mainly filled by PlioQuaternary volcanic rocks and sediments.

The Somma-Vesuvius edifice is interested by two main fault systems: (a) the NE-SW system involves the northwestern sector of Mt. Somma, where probably dips to dislocate the sedimentary basement; (b) the NW-SE structures involve the northeastern sector of the Somma edifice and extend to the southwestern sector of Mt. Vesuvius. Eruptive fissures, aligned along the strike of the main faults and in E-W and N-S directions, affect the Mt. Somma edifice and the southern and western flanks of Mt. Vesuvius. The volcanism is controlled by the compressive tectonics determined by the Adriatic slab dynamics [Piochi et al. 2005].

The eruptive history of the last $20 \mathrm{ky}$ is signed by at least 4 plinian eruptions: Pomici di Base (18-20 ky), Mercato (8.0 ky), Avellino (3.9 ky), and Pompei (79 A.D). These main episodes were intercalated by sub-plinian eruptions (Pomici Verdoline, 16 ky; Pollena, 472 A.D.; 1631 eruption), by minor strombolian and effusive activity, and by quiescent periods [Arrighi et al. 2001, Cioni et al. 2008 and references therein]. After 1631 a persistent open-conduit activity began, which terminated with the violent strombolian eruption of 1944 [Santacroce 1987, Arrighi et al. 2001].

Since then the volcano has been characterized by hydrothermal activity with diffuse $\mathrm{CO}_{2}$ degassing and low-temperature fumaroles in the crater area, thermal submarine emissions, low energy, and discontinuous seismic activity [Chiodini et al. 2001, Saccorotti et al. 


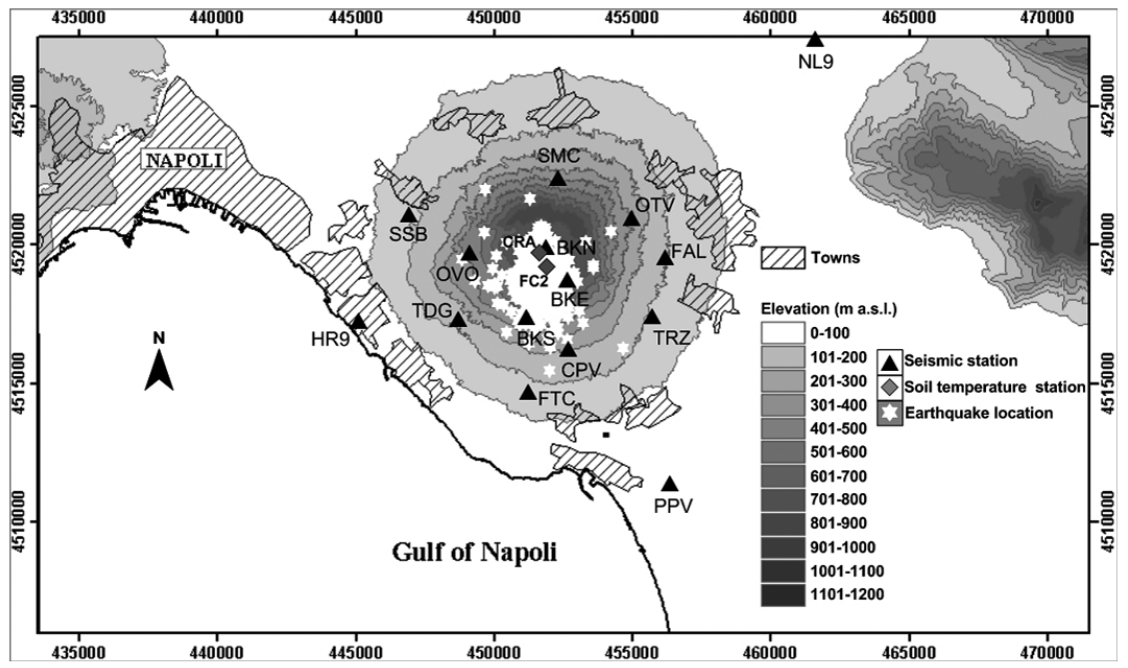

Figure 1. Map of the Vesuvius area plotting the locations of earthquakes and stations of the seismic and geochemical surveillance networks.

2002, Frondini et al. 2004, Caliro et al. 2011]. These activities could be mainly reconducted to the hydrothermal fluid circulation inside the volcanic edifice. Chiodini et al. [2001] hypothesize the presence of a deep hydrothermal reservoir at depths of roughly $2.5-5.0 \mathrm{~km}$, within the carbonate sequence, underneath the crater area. This reservoir, characterized by the presence of $\mathrm{NaCl}$ solutions or halite saturated brines, would be subjected to fluid overpressures whose discharge through fracturing rocks could explain the seismic crises.

\subsection{The stress field acting on Mt. Vesuvius}

The seismicity at Mt. Vesuvius consists of VT earthquakes, which concentrate at depths shallower than about $4 \mathrm{~km}$ below sea level (b.s.l.) along the crater axis. The maximum of the hypocentral distribution is at a depth of 2-3 km, which corresponds to the transition between the collapsed (caldera) central sector of the volcanic edifice and the carbonate basement [Saccorotti et al. 2002, Scarpa et al. 2002, Del Pezzo et al. 2004].

Strike-slip, normal and reverse dip-slip are the typical focal mechanisms associated to Vesuvian earthquakes, with nodal planes mainly oriented along the NW-SE and NE-SW directions [Bianco et al. 1998]. Two main orientations exist for the P (NNE-SSW and ESE-WNW) and T (ESE-WNW and NNE/N-SSW / S) axes [Bianco et al. 1998, Zollo et al. 2002].

The deepest events have an average stress drop between 1 and $10 \mathrm{MPa}$ and are probably caused by the regional tectonic stress, which concentrates in the prefractured carbonate basement [Del Pezzo et al. 2004]. The shallowest earthquakes are characterized by stress drop up to $1 \mathrm{MPa}$ and are likely triggered by an increase of pore fluid pressure generated by changes in the level of the hydrothermal aquifer, whose top is located at about $1 \mathrm{~km}$ b.s.l. beneath the crater [Del Pezzo et al. 2004].

The last relevant seismic crisis started in August
1999 and reached the maximum rate in October 1999, when more than 140 earthquakes were recorded. The strain release reached $5.6 \cdot 10^{9}$ Joule and the maximum magnitude earthquake $\left(M_{D}=3.6\right)$ occurred at 07:41 UT on October 9 , at about $4 \mathrm{~km}$ b.s.l. inside the carbonate basement, beneath the crater area. The magnitude of this event was the highest recorded since the last eruption of 1944. The event was generated by tectonic stress release along a pre-existing fracture system and had a stress drop of about $10 \mathrm{MPa}$ [Ventura and Vilardo 1999, Zollo et al. 2002, Del Pezzo et al. 2004]. The seismic crisis continued with lower-magnitude events and lasted until November 1999. After this sequence, the seismic activity decreased to a lower level.

\subsection{The fumarolic field}

The fumarolized area of the 1944 crater is characterized by the presence of vents distributed between its rim and the bottom. Fumaroles discharge fluids with different temperature and chemical composition. Fumaroles located on the crater rim are mainly composed of water vapor and atmospheric gases at temperature lower than $75^{\circ} \mathrm{C}$ [Caliro et al. 2011]. Fumarolic vents at crater bottom show discharge temperature of about 95 ${ }^{\circ} \mathrm{C}$ and a chemical composition with $\mathrm{H}_{2} \mathrm{O}$ and $\mathrm{CO}_{2}$ as major components, followed by other species as $\mathrm{H}_{2}$, $\mathrm{H}_{2} \mathrm{~S}, \mathrm{~N}_{2}, \mathrm{CH}_{4}$, $\mathrm{CO}$ and $\mathrm{He}$ [Caliro et al. 2011], whose origin is related to a high-temperature hydrothermal system located below the crater [Chiodini et al. 2001].

\section{Data description and methods}

We performed the comparison between fumarole temperature and seismological parameters by using data acquired since 1998 .

The seismic activity at Vesuvius volcano has been monitored continuously by a permanent seismic network (Figure 1) managed since 1972 by the Osservato- 


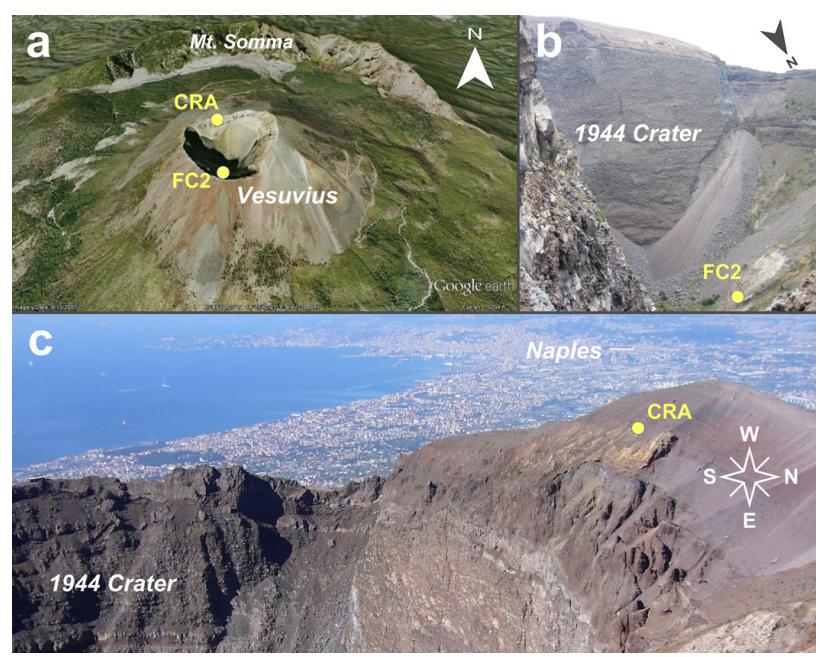

Figure 2. From top to bottom, clockwise: a) aerial view of the Mt. Somma-Vesuvius complex (source of image: Google Earth) with the locations of fumarole temperature monitoring stations; b) picture taken from the north-western rim of the 1944 crater illustrating the position of FC2 station; c) picture taken from the top of Mt. Vesuvius illustrating the position of CRA station.

rio Vesuviano (OV), now Istituto Nazionale di Geofisica e Vulcanologia (INGV). At present, the seismic network is composed by 10 analogical stations equipped with short-period geophones, of which 3 are three- and 7 single-component; 2 short-period, three-component digital stations; and 6 broadband, three-component digital stations. The employed sensors are $1 \mathrm{~Hz}$ velocimeter Geotech S13 and Mark LE-3D, and broadband Guralp CMG 40T and Trillium 120P. The signals are acquired in continuous mode with a sampling rate of 100 $\mathrm{Hz}$ and are telemetered to the acquisition centre in Naples [Giudicepietro et al. 2010].

Currently 4 digital stations of the Mobile Seismic Network operate at Mt. Vesuvius. They consist of Lennartz Marslite and Nanometrics Taurus dataloggers, equipped with three-component broadband sensors, Guralp CMG-40T or Lennartz LE3D/20s. The data are locally stored at sampling rate of $125 \mathrm{~Hz}$ or 100 Hz. Details are in Castellano et al. [2012].

The historical seismic catalogue of Mt. Vesuvius contains the duration magnitude $\left(M_{D}\right)$ for the VT earthquakes since 1972. Magnitude is estimated at OVO station, located in the western sector of the volcano.

Hourly data of soil temperature were acquired in two low temperature $\left(<100{ }^{\circ} \mathrm{C}\right)$ fumaroles, identified by the acronyms FC2 and CRA (previously identified as VESA in M08), located at the bottom and on the northern rim of the crater, respectively (Figures 1, 2). The acquisition periods were between February 2004 and January 2005 for FC2 and between April 2005 and September 2010 for CRA; the latter went out of order in September 2010 and was replaced with a new station in July 2011. Temperature was measured at $30 \mathrm{~cm}$ depth using a waterproof, 12 bit Gemini Tinytag Plus 2 logger, equipped with an external measuring probe at a resolution of $0.06^{\circ} \mathrm{C}$.

Rainfall data until July 2007 are a courtesy of Mt. Vesuvius National Park and were acquired in a meteorological station located few tens of meters apart of CRA. The rest of the data series, until October 2010, was reconstructed from data acquired in the closest available station, located at Pozzuoli, about $20 \mathrm{~km}$ west of Mt. Vesuvius (Regional Campanian Agro-meteorological Center, available on line at the URL http:/ / www.sito. regione.campania.it/agricoltura/meteo/agrometeo.htm), using a linear regression algorithm based on common data between the two stations (Pozzuoli and Vesuvius) for the period June 2003-July 2007.

\section{Summary of seismological and geochemical ob- servations in 1998-2005}

M08 analyzed both short- and long-term variations in geochemical and seismic parameters for the Vesuvius volcanic-hydrological system in the period 1998-2005. They interpreted these variations as having common source mechanisms.

\subsection{Long-term trends}

In the period of observation, the salinity and dissolved carbon content of groundwaters indicate that the contribution of the deeper saline and gas-charged waters was higher from 2001 to 2003, while it significantly decreased in 1999 and after late 2003, with a major contribution of shallower cold and dilute water. In the latter period, the increasing contribution of the shallower water was also evidenced by a decrease in well temperature, while air temperature and rainfall remained steady.

The number of seismic events and energy release also exhibited coeval variations. The seismic parameters showed a peak in correspondence of the October 1999 crisis, with deep and high-stress drop earthquakes, occurred in the pre-fractured carbonate basement in response to the regional tectonic stress release [Del Pezzo et al. 2004]. After the crisis, the seismic activity decreased to a very low level, with earthquakes characterized by shallow hypocenters and low-stress drop, mainly clustered within the volcanic edifice. This seismicity was mainly triggered by pore fluid pressure variations, in turn caused by the charge/ discharge mechanism of the shallow aquifer or by perturbations of the local stress field. After August 2004, the number of earthquakes increased slightly.

In the periods of higher seismicity, related to variations in the regional stress field or to pore fluid pressure, the chemistry of the aquifer resulted more affected by the shallow diluted water. This effect sug- 
gests the influence of variations in the strain field on the groundwater chemistry and can be due to local permeability changes (i.e., opening or closing of microcracks and fractures).

\subsection{Short-term trend}

On August 30, 2005, a very shallow earthquake (hypocenter at $300 \mathrm{~m}$ a.s.l., green star in Figure 3A), with a magnitude value $\left(M_{D}=2.8\right)$ particularly high for the area, occurred during a phase of slight enhancement of seismicity. The location and the low stress drop of this earthquake suggested that it was triggered by the pressure increase in the fluids circulating close or within the central conduit. This hypothesis was also supported by the moment tensor analysis, which is consistent with a tensile crack opening along the direction orthogonal to the maximum stress axis of a shear failure. The opening could have been enhanced by the increase of pore fluid pressure that gradually lowered the cohesion, favoring a shear rupture. The pore pressure build-up could be due to the stress field acting locally on the upper portion of central conduit and would consequentially enhance the upwelling of thermal fluids toward the surface, leading to the thermal anomaly observed at the VESA station (now CRA station) a few days before the earthquake.

\section{Seismological and geochemical patterns in 1999- 2011}

We have updated the monthly distribution of VT number and energy release presented in M08 (Figures $3 \mathrm{~B}$ and $\mathrm{C}$, respectively). The data set refers to the temporal interval from January 1999 to December 2011. In the distribution calculation we have considered the earthquakes contained in the seismic catalogue for the OVO station (available at http:/ / www.ov.ingv.it/ov/it/ banche-dati/ 186-catalogo-sismico-del-vesuvio.html). The energy temporal distribution is calculated from the Gutenberg-Richter relationship as function of duration magnitude $M_{D}$ [Lay and Wallace 1995]

$$
\log (E)=9.9+1.9 M_{D}
$$

where the energy $E$ is expressed in erg and the $M_{D}$ values are extracted from the historical catalogue of the OVO station.

For the whole data set, the long term trend of seismic parameters in the period 1999-2011 can be schematized as follows (Figures 3B,C):

1) The seismicity rate and the corresponding energy level started to decrease after the seismic crisis of 1999.

2) The seismicity reached minimum values in May 2001-July 2004; from January 2000 to December 2005,

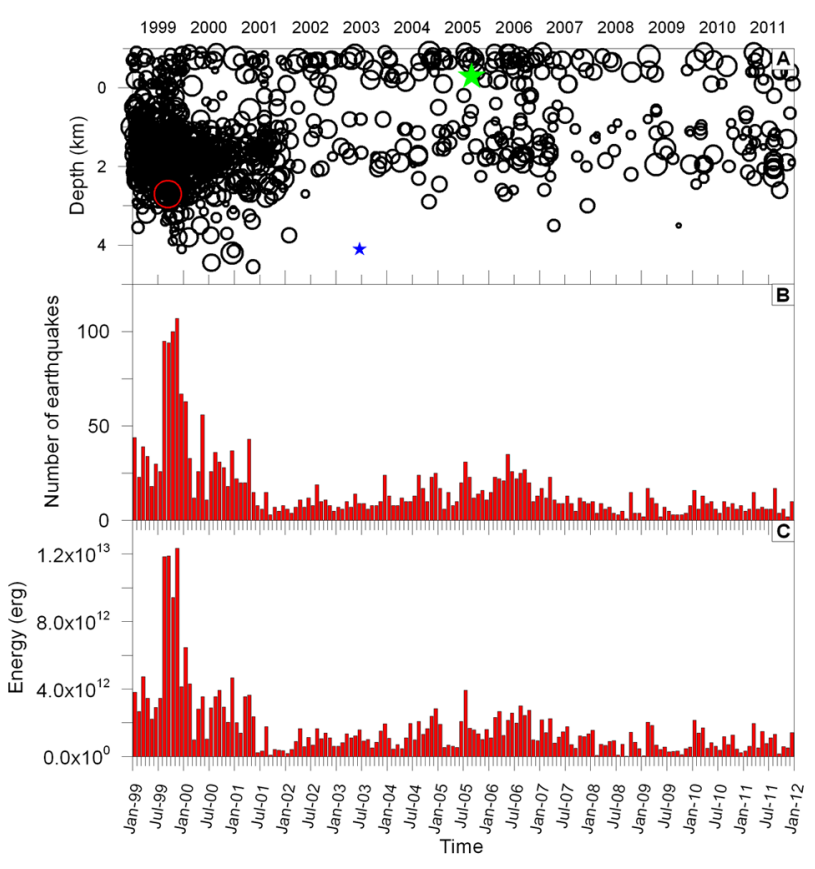

Figure 3. Seismic parameters of Mt. Vesuvius VT earthquakes from 1999 to 2011: (A) source depth $(\mathrm{km})$; (B) monthly distribution of number of events; (C) energy (erg). The reported data are extracted from OV historical catalogue for the period January 1999-December 2011. The size of each symbol in panel A is proportional to the magnitude. The blue star indicates the July 20, 2003, Long Period earthquake, the green star the August 30, 2005, earthquake and the red circle the October 9, 1999, $M_{D} 3.6$ earthquake.

the energy release decreased.

3) The seismicity rate slightly increased after $\mathrm{Au}$ gust 2004.

4) The seismicity rate reached a relative maximum in summer 2006, and then returned to very low value. A similar but less evident behavior can be retrieved for the seismic energy.

The observations 1-3 were validated in M08 by a change-point test [Mulargia and Tinti 1985], while a very stable trend for the seismicity rate after July 2008 has been detected with the updated data by using the Kolmogorov-Smirnov distribution [Press et al. 1992]. In particular, we found a constant linear behavior with a rake of about $2^{\circ}$ and a regression coefficient of 0.94 .

In Figure 3A we show the depth of the VTs as function of time. The hypocentral depths are obtained from a 3D probabilistic location procedure (NonLinLoc) [Lomax et al. 2000]. The corresponding epicenters are reported in Figure 1. It can be seen that:

1) Starting from 2001 the seismicity lacks deep $(>2.5$ $\mathrm{km}$ ) hypocenters. The depth is in the upper $0-2 \mathrm{~km}$ of the crust.

2) The decrease of deep seismicity culminates in 2005, when the very shallow earthquake of 30 August 2005 occurred.

It is noteworthy the occurrence of an anomalous Long Period earthquake (quasi-monochromatic spec- 


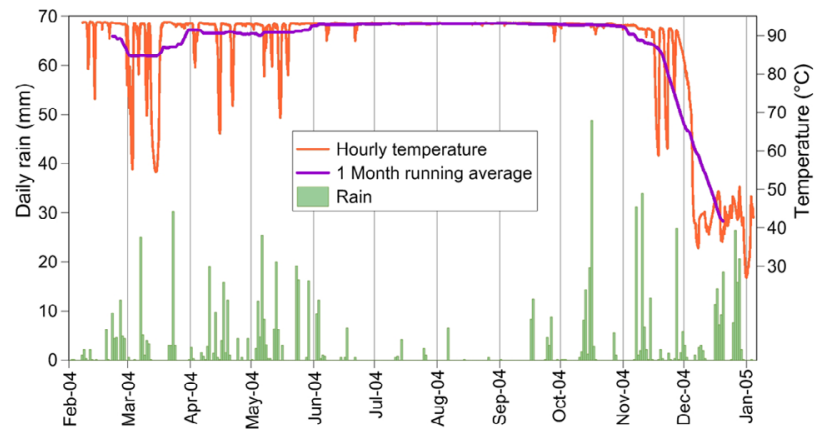

Figure 4. Top: hourly temperature (orange line) measured at $30 \mathrm{~cm}$ depth at FC2 station and its 1 month-running average (purple thick line); bottom: monthly rainfall amounts (green bars). Data refers to the period from February to December 2004.

trum picked at $3.9 \mathrm{~Hz}$ ) recorded by the OV seismic stations on July 20, 2003 [Bianco et al. 2005]. This deep seismic event, located about $4 \mathrm{~km}$ b.s.l., has a probable hydrothermal origin. Array analysis indicates the presence of $\mathrm{P}$ and $\mathrm{S}$ wave in the first 2 seconds of the signals [Bianco et al. 2005]. It is indicated with a blue star in Figure $3 \mathrm{~A}$ and, obviously, it is not included in the calculation of VT distributions in Figures 3B and C.

Continuous monitoring of soil temperature started at fumarole FC2, located at the bottom of the 1944 crater (Figure 2). Available data, ranging from February 2004 to January 2005, are presented in Figure 4 together with daily values of rainfall amounts. As shown in the figure, the main feature of the signal is the buffering at $\sim 94^{\circ} \mathrm{C}$, that is the water boiling temperature at the altitude of the crater bottom.

The medium term (months) trend is affected by short lasting (days) cooling cycles mainly linked to rainfalls. The effect of rainfall on decreasing soil temperature depends on the amount of water effectively infiltrating in the soil, in turn related to air temperature, humidity and rainfall rate.

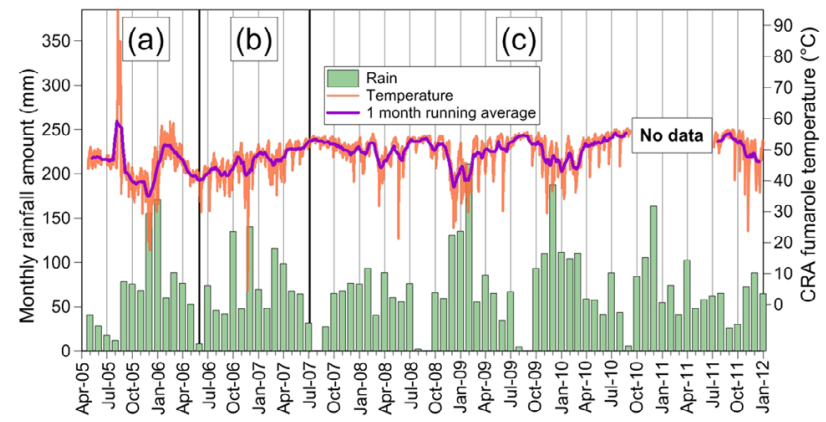

Figure 5. Top: hourly temperature (orange line) measured at $30 \mathrm{~cm}$ depth at CRA station and its 1 month-running average (purple thick line); bottom: monthly rainfall amounts (green bars). (a), (b) and (c) indicate the three phases in which the studied period was subdivided (see text for details). Data refers to the period from April 2005 to December 2011.
Once excluded hydrological modulations, the only evident anomalous feature is the huge temperature drop recorded from the beginning of December 2004 to the end of the observations (January 2005), during which soil temperature halved to $45^{\circ} \mathrm{C}$.

Due to serious environmental issues in ensuring a continuous record from fumarole $\mathrm{FC} 2$, mainly due to the high corrosion rate of the sensors determined by the acidic gases emitted by the vents and the difficulties to safely access the crater bottom, a new monitoring point was established in April 2005 on the northern sector of the crater rim (CRA in Figure 2). Figure 5 shows the hourly data of soil temperature acquired at CRA station (orange line), their monthly running average (purple thick line) and the total monthly rainfall amount (green bars). Three phases, labeled from (a) to (c) in the figure, each characterized by a different dynamic of the thermal signal, may be recognized in the studied period:

(a) The first phase, from the beginning of observations in April 2005 to June 2006, was dominated by the thermal anomalies driven by the August 2005 shallow earthquake. A huge thermal anomaly, with a maximum of $\sim 95{ }^{\circ} \mathrm{C}$ (the highest value of the entire observational period) was recorded several days before the earthquake, after which soil temperature diminished first rapidly and later with a more gentle slope to a minimum of $\sim 20^{\circ} \mathrm{C}$ observed in December 2005 . After, soil temperature rose up to a relative maximum of $\sim 60^{\circ} \mathrm{C}$ in February 2006, followed by a relative minimum of $\sim 30{ }^{\circ} \mathrm{C}$ in June 2006, in complete counter tendency with respect to the normal seasonal cycle.

(b) The second phase, characterized by a strong variability of the temperature, was followed by a period during which soil temperature, even if with some modulation induced by rainfall events, progressively rose up from $40{ }^{\circ} \mathrm{C}$ in June 2006 to $\sim 50{ }^{\circ} \mathrm{C}$ observed in July 2007. It is noteworthy the negative spike recorded at the beginning of December 2006 with a minimum of less than $10{ }^{\circ} \mathrm{C}$ (the main minimum of the entire observational period), very similar to that observed on December 2004 at fumarole FC2 (see Figure 4).

(c) The third and last phase, from July 2007 to December 2011, was characterized by a more regular thermal signal with respect to the previous phases, with the absence of significant maxima and with relative minima modulated by rainfall.

\section{Discussion}

In Figure 6 we present a synthesis of all the results obtained in this study together with the time variation of $\mathrm{CO}_{2} / \mathrm{CH}_{4}$ ratio from Caliro et al. [2011] useful to interpret our observations.

In the period January 1999-December 2011, seis- 


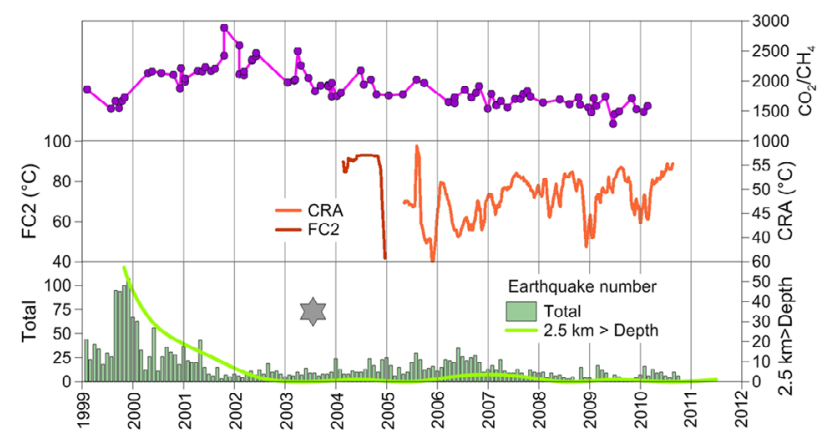

Figure 6. Synthesis of the main results in the period 1999-2011. From top to bottom: time variation of $\mathrm{CO}_{2} / \mathrm{CH}_{4}$ ratio (data from Caliro et al. [2011], purple circled line), FC2 temperature (1 month running average, ruby red thick line) and CRA temperature (1 month running average, orange thick line), number of total localizable VT (green bars) and number of events with hypocenters deeper than $2.5 \mathrm{~km}$ (acid green thick line). The gray star at the bottom identifies the July 20, 2003, Long Period seismic event.

mic and fumarolic activities show coeval trends:

- The pattern of number of earthquakes, strongly influenced by deep (deeper than $2.5 \mathrm{~km}$ b.s.l.) events linked to the October 1999 crisis, showed a fast decay toward a minimum in 2001. Between the end of 2001 and the first months of 2002, Caliro et al. [2011] observed the highest pressure in the hydrothermal aquifer. They found contemporary maxima in several markers of an enhanced contribution of fluids of deep (magmatic) origin, as the equilibrium pressure of carbon dioxide $\left(\mathrm{PCO}_{2}\right)$ and the ratios $\mathrm{CO}_{2} / \mathrm{CH}_{4}$ (shown in Figure 6), $\mathrm{CO}_{2} / \mathrm{H}_{2} \mathrm{O}$ and $\mathrm{He} / \mathrm{CO}_{2}$. By the first half of 2002, these parameters indicated the occurrence of a new depressurization phase of the hydrothermal aquifer.

- The constant depressurization trend was interrupted at the end of July 2003 in correspondence of an anomalous seismic event, interpreted as linked to the presence of hydrothermal fluids. Striking anomalies in geochemical parameters followed. A detailed discussion about this point is reported in Cusano et al. [2013] and Federico et al. [2013].

- After the July 2003 anomalies, the depressurization trend regained with major evidence. A marked and sudden fall of FC2 fumarole temperature occurred between the end of 2004 and the first days of 2005.

- The positive trend of seismicity proceeded toward a relative maximum, reached in the first half of 2006 and preceded by the shallow earthquake of August 2005. As already described in M08 and now confirmed by the temperature anomalies recorded at CRA, this earthquake likely perturbed the steam flux in the crater rim. Its effects were visible since the first half of 2006.

- After this long series of seismic and geochemical anomalies, lasted five years (2002-2006), nothing more noticeable is observed in our data until the end of the observational period (end of 2011).
From the results obtained on the whole dataset, we find a confirmation for the long-term trend common to seismic and geochemical parameters already identified in M08. We can hypothesize two main stages. The first one, lasting from 1999 to the end of 2001/beginning of 2002 , is mostly dominated by the effects of the volcanotectonic stress on both seismicity and geochemical parameters, as described in M08. The second stage starts in 2002-03 and is characterized by the progressive depletion of these effects. In this stage, deep earthquakes, characterizing the most recent crises (August-November 1995, February-May 1996, January-April 1999 and August-November 1999) and interpreted by Saccorotti et al. [2002] as due to the migration of the rupture front from the surface down to about 5 to $6 \mathrm{~km}$ b.s.l., practically disappear. Conversely, the observed oscillations in the seismicity rate can be mainly ascribed to pore fluid pressure variations, as the characteristics of most earthquakes (i.e., shallow source depth and low energy) would suggest [Del Pezzo et al. 2004]. In a system close to the failure threshold, small variations of fluid pressure, lubricating the pre-existing fracture system, are able to eventually trigger seismicity [Hill 1977, Sibson 1996, Saccorotti et al. 2002]. Pore pressure variations can be caused by the charge/discharge mechanism of the shallow aquifer, by perturbations in the local strain field or by the increased outgassing of hydrothermal/magmatic systems. Actually, gas discharge rate and composition of crater fumaroles claim for the enhanced output of hydrothermal/magmatic gases in the period 2000-2003 [Caliro et al. 2011], thus confirming the role of fluids in generating seismicity in the shallow parts of the volcanic edifice (Figure $3 \mathrm{~A}$ ). Indeed, the shallow earthquake of August 2005 has been heralded by a sharp increase of the temperature of fumarole CRA (Figure 5 and M08), thus re-enforcing the idea that fluid pressurization can generate seismicity. Analogously, the reduced output of deep fluids from crater fumaroles [Caliro et al. 2011] since 2002, remarked by a decrease of soil $\mathrm{CO}_{2}$ flux (Figure 6), would have been provoked by a general depressurization of the volcano-hydrothermal system, as testified by a peculiar event occurred on July 2003 at about $4 \mathrm{~km}$ of depth. According to Cusano et al. [2013], this LP earthquake was generated in a fluid-filled volume; a consequent pressure drop in the neighbour rock could have favored the circulation of shallower fluids, thus explaining several changes in chemical composition and saline content [Federico et al. 2013]. Moreover, the pressure drop could be responsible of some episodes of drastic soil temperature decrease, as observed at FC2 station in late 2004 and CRA station in mid 2006. It is worth of note that this latter occurred in correspondence of the peak of seismicity recorded in 2006. 


\section{Conclusions}

This work indicates that, since 2002, both seismicity and soil temperature are mainly controlled by pore fluid pressure variations, as the characteristics of most earthquakes would suggest (i.e., shallow source depth and low energy). Hot fluid circulation in the crater area varies during time as an effect of both meteorological causes (i.e., rainfall) and the local stress field. The decrease of the deep fluid output from the crater fumaroles, recorded since 2002, paralleled by a general de-pressurization of the volcano-hydrothermal system, could have induced some episodic fluctuations in the pattern of steam circulation in the Vesuvius cone. Pressure drops can induce vapor separation from hot water at temperature close to boiling, locally increase steam pressure and generate in turn rock failure, as observed in August 2005.

On the other hand, rock fracturing and enhanced permeability would promote circulation of shallow (colder) fluids at greater depth, thus decreasing soil temperature, as occurred in late 2004 or in 2006, in correspondence of a relative increase of seismicity. A close relationship is confirmed between seismicity and hot fluid circulation, both playing a reciprocal role, and it appears probably related to the stress field acting on the volcano.

We want to conclude by remarking the utility of long-lasting and multidisciplinary monitoring of quiescent volcanoes. The possibility of characterizing the behavior of the volcanic activity and understanding the dynamical processes that define the state of a volcano, such as Mt. Vesuvius, could deal with the lack of a statistics regarding the signals which lead to eruptions.

Acknowledgements. Daniele Andronico and Guido Ventura are fully acknowledged for their useful comments.

\section{References}

Acocella, V., and R. Funiciello (2006). Transverse systems along the extensional Tyrrhenian margin of central Italy and their influence on volcanism, Tectonics, 25 (2); doi:10.1029/2005TC001845. ISSN: 0278-7407.

Arrighi, S., C. Principe and M. Rosi (2001). Violent strombolian and subplinian eruptions at Vesuvius during post-1631 activity, Bull. Volcanol., 63 (2), 126150; doi:10.1007ls004450100130.

Bianco, F., M. Castellano, G. Milano, G. Ventura and G. Vilardo (1998). The Somma-Vesuvius stress field induced by regional tectonics: Evidences from seismological and mesostructural data, J. Volcanol. Geoth. Res., 82, 199-218; doi:10.1016/S0377-0273 (97)00065-6.

Bianco, F., P. Cusano, S. Petrosino, M. Castellano, C.
Buonocunto, M. Capello and E. Del Pezzo (2005). Small-aperture Array for Seismic Monitoring of Mt. Vesuvius, Seismol. Res. Lett., 76 (3), 344-355; doi:10.1785/gssrl.76.3.344.

Caliro, S., G. Chiodini, R. Avino, C. Minopoli and B. Bocchino (2011). Long time-series of chemical and isotopic compositions of Vesuvius fumaroles: evidence for deep and shallow processes, Annals of Geophysics, 54 (2), 2011; doi:10.4401/ag-5034.

Castellano, M., D. Galluzzo, M. La Rocca and M. Capello (2012). Lo studio dei vulcani attivi e delle strutture crostali con reti sismiche temporanee: storia, evoluzione e prospettive della Rete Sismica Mobile dell'Osservatorio Vesuviano (INGV), Quaderni di Geofisica, INGV, no. 97, 51 pp. ISSN:1590-2595.

Chiodini, G., L. Marini and M. Russo (2001). Geochemical evidence for the existence of high-temperature hydrothermal brines at Vesuvio volcano, Italy, Geochim. Cosmochim. Acta, 65, 2129-2147.

Cioni, R., A. Bertagnini, R. Santacroce and D. Andronico (2008). Explosive activity and eruption scenarios at Somma-Vesuvius (Italy): towards a new classification scheme, J. Volcanol. Geoth. Res., 178, 331-346; doi:10.1016/j.jvolgeores.2008.04.024.

Cusano P., S. Petrosino, F. Bianco and E. Del Pezzo (2013). The first Long Period earthquake detected in the background seismicity at Mt. Vesuvius, Annals of Geophysics, 56 (4), S0440; doi:10.4401/ag6447.

D’Auria, L., F. Giudicepietro, I. Aquino, G. Borriello, C. Del Gaudio, D. Lo Bascio, M. Martini, G.P. Ricciardi, P. Ricciolino and C. Ricco (2011). Repeated fluid transfer episodes as a mechanism for the recent dynamics of Campi Flegrei caldera (1989-2010), J. Geophys. Res., 116, B04313; doi:10.1029/2010JB007837.

Del Pezzo, E., F. Bianco and G. Saccorotti (2004). Seismic source dynamics at Vesuvius volcano, Italy, J. Volcanol. Geoth. Res., 133, 23-39; doi:10.1016/S037 7-0273(03)00389-5.

Di Renzo, V., M.A. Di Vito, I. Arienzo, L. Civetta, M. D’Antonio, F. Giordano, G. Orsi and S. Tonarini (2007). Magmatic history of Somma-Vesuvius on the basis of new geochemical and isotopic data from a deep borehole (Camaldoli della Torre), J. Petrol., 48 (4), 753-784; doi:10.1093/petrology/egl081.

Federico, C., P. Madonia, P. Cusano and S. Petrosino (2013). Groundwater geochemistry of the Mt. Vesuvius area: implications for volcano surveillance and relationship with hydrological and seismic signals, Annals of Geophysics, 56 (4), S0447; doi:10.4401/ag6453.

Frondini, F., G. Chiodini, S. Caliro, C. Cardellini, D. Granieri and G. Ventura (2004). Diffuse $\mathrm{CO}_{2}$ de- 
gassing at Vesuvio, Italy, Bull. Volcanol., 66, 642-651; doi:10.1007/s00445-004-0346-x.

Giudicepietro, F., M. Orazi, G. Scarpato, R. Peluso, L. D’Auria, P. Ricciolino, D. Lo Bascio, A.M. Esposito, G. Borriello, M. Capello, A. Caputo, C. Buonocunto, W. De Cesare, G. Vilardo and M. Martini (2010). Seismological Monitoring of Mount Vesuvius (Italy): More than a Century of Observations, Seismol. Res. Lett., 81 (4), 625-634; doi: 10.1785/gssrl. 81.4.625.

Hill, D.P. (1977). A model for earthquake swarms, J. Geophys. Res., 82, 1347-1352; doi:10.1029/JB082i00 $8 \mathrm{p} 01347$.

Lay, T., and T. Wallace (1995). Modern Global Seismology, San Diego (California), Elsevier.

Lomax, A., J. Virieux, P. Volant and C. Berge (2000). Probabilistic earthquake location in 3D and layered models: Introduction of a Metropolis-Gibbs method and comparison with linear locations, In: C.H. Thurber and N. Rabinowitz (eds.), Advances in Seismic Event Location, Amsterdam, Kluwer, 101-134.

Madonia, P., C. Federico, P. Cusano, S. Petrosino, A. Aiuppa and S. Gurrieri (2008). Crustal dynamics of Mount Vesuvius from 1998 to 2005: Effects on seismicity and fluid circulation, J. Geophy. Res., 113, B05206; doi:10.1029/2007JB005210.

Marzocchi, W., R. Scandone and F. Mulargia (1993). The tectonic setting of Mount Vesuvius and the correlation between its eruptions and the earthquakes of the southern Apennines, J. Volcanol. Geoth. Res., 58, 27-41; doi:10.1016/0377-0273(93)90100-6.

Mauri, G., G. Williams-Jones, G. Saracco and J.M. Zurek (2012). A geochemical and geophysical investigation of the hydrothermal complex of Masaya volcano, Nicaragua, J. Volcanol. Geoth. Res., 227/228, 15-31; doi:10.1016/j.jvolgeores.2012.02.003.

Mulargia, F., and S. Tinti (1985). Seismic sample areas defined from incomplete catalogues: An application to the Italian territory, Phys. Earth Planet. Inter., 40, 273-300; doi:10.1016/0031-9201(85)90038-X.

Patacca, E., R. Sartori and P. Scandone (1990). Tyrrhenian basin and Apenninic arcs: kinematic relations since Late Tortonian times, Mem. Soc. Geol. Ital., 45, 425-451.

Piochi, M., P.P. Bruno and G. De Astis (2005). Relative roles of rifting tectonics and magma ascent processes: Inferences from geophysical, structural, volcanological, and geochemical data for the Neapolitan volcanic region (southern Italy), Geochem. Geophys. Geosyst., 6, Q07005; doi:10.1029/2004GC000885.

Press, W.H., S.A. Teukolsky, W.T. Vetterling and B.P. Flannery (1992). Numerical Recipes in C: The Art of Scientific Computing, New York, Cambridge
Univ. Press.

Saccorotti, G., G. Ventura and G. Vilardo (2002). Seismic swarms related to diffusive processes: The case of Somma-Vesuvius volcano, Italy, Geophysics, 67 (1), 199-203; doi:10.1190/1.1451551.

Santacroce, R., ed. (1987). Somma-Vesuvius, Quaderni de "La Ricerca Scientifica", CNR, 114 (Progetto finalizzato Geodinamica, Monografie finali, 8), 251 pp., 4 tables.

Scandone, R., F. Bellucci, L. Lirer and G. Rolandi (1991). The structure of the Campanian Plain and the activity of the Neapolitan volcanoes (Italy), J. Volcanol. Geoth. Res., 48, 1-31; doi:10.1016/03770273(91)90030-4.

Scarpa, R., F. Tronca, F. Bianco and E. Del Pezzo (2002). High resolution velocity structure beneath Mount Vesuvius from seismic array data, Geophys. Res. Lett., 29 (21), 2040; doi:10.1029/2002GL015576.

Shinohara, H., N. Matsushima, K. Kazahaya and M. Ohwada (2011). Magma-hydrothermal system interaction inferred from volcanic gas measurements obtained during 2003-2008 at Meakandake volcano, Hokkaido, Japan, Bull. Volcanol., 73, 409-421; doi: 10.1007/s00445-011-0463-2.

Sibson, R.H. (1996). Structural permeability of fluiddriven faultfracture meshes, J. Struct. Geol., 18 (8), 1031-1042.

Ventura, G., and G. Vilardo (1999). Slip tendency analysis of the Vesuvius faults: Implications for the seismotectonic and volcanic hazard assessment, Geophys. Res. Lett., 26 (21), 3229-3232; doi:10.1029/ 1999GL005393.

Zollo, A., W. Marzocchi, P. Capuano, A. Lomax and G. Iannaccone (2002). Space and time behavior of seismic activity at Mt. Vesuvius volcano, southern Italy, Bull. Seismol. Soc. Am., 92 (2), 625-640; doi:10.178 5/0120000287.

\footnotetext{
${ }^{\star}$ Corresponding author: Paola Cusano, Istituto Nazionale di Geofisica e Vulcanologia, Sezione di Napoli, Osservatorio Vesuviano, Naples, Italy; email: paola.cusano@ov.ingv.it.

(C) 2013 by the Istituto Nazionale di Geofisica e Vulcanologia. All rights reserved.
} 